\title{
Linfangioma en labio inferior: una presentación inusual
}

\author{
Rodríguez Romero FJ*, Báez Perea JM**, Muriel Cueto PJ***
}

\section{RESUMEN}

El linfangioma es un tumor benigno, hamartomatoso del sistema linfático. Por lo general afecta a la cabeza y al cuello. Mas que una neoplasia verdadera se le considera una lesión del desarrollo. La mayor parte de los linfangiomas, están presentes en el nacimiento (60\%) y a los 2 años entre el 80 y el $90 \%$. Cuando afecta a la boca, la lengua es la zona mas afectada en sus 2/3 partes anteriores. La localización insólita de la lesión en el labio inferior y la edad de la paciente lo hace un caso inusual; pocos casos han sido relatados en la literatura.

Palabras claves: Linfangioma, Linfangioma circunscrito.

\section{ABSTRACT}

The lymphangioma is a beningn, hamartomatous tumor of the lymphatic system. It is usually found in the head and neck region and is widely regarded as a developmental lesion rather than a true neoplasia. Most lymphangiomas are present at birth (60\%), and by the age of 2 years $80 \%$ to $90 \%$ are present. When lymphangioma occurs in the mouth, the anterior two thirds of the tongue is the most commonly affected region. The isolated location of the lesion in the lower lip and the age of the patient are unusual; few cases have been reported in the literature.

Key words: Lymphangioma, Lymphangioma circumscriptum.

Fecha de recepción: Mayo 2007.

Aceptado para publicación: Junio 2007.

* Doctor en Estomatología por la P.U.C.M.M. Dentista de Atención Primaria, Distrito "Cádiz -La Janda". Centro de Salud "La Paz". Cádiz.

** Profesor Titular de Anatomía Patológica en la Universidad de Cádiz. Facultativo Especialista de Área, Servicio de Anatomía Patológica. Hospital Clínico Universitario "Puerta del Mar”. Cádiz.

*** Médico Residente. Servicio de Anatomía Patológica. Hospital Clínico Universitario "Puerta del Mar". Cádiz.

Rodríguez Romero FJ, Báez Perea JM, Muriel Cueto PJ. Linfangioma en labio inferior: una presentación inusual. Av. Odontoestomatol 2008; 24 (3): 203-210.

\section{INTRODUCCIÓN}

El linfangioma es una tumoración benigna de los vasos linfáticos que dejan espacios vasculares revestidos por células endoteliales y en cuyo interior se encuentra líquido linfático rico en proteínas y pocas células linfáticas. (3) De crecimiento indoloro, progresivo y de pronostico bueno. Pueden presentarse asociados a hemangiomas (18) y se denominan hemangiolinfangioma. También llamados: linfangio- 
mas, higroma quístico, linfangioma circunscrito y linfangiomatosis, siempre son congénitos. (18) Al igual que el hemangioma, se trata de una anomalía congénita más que de una verdadera neoplasia.

Tienen una marcada predilección por la cabeza y el cuello, donde aparecen el $75 \%$ de los casos. (3) El higroma quístico aparece sobre todo en axila y cuello debido al tejido mas laxo de esta zona, que facilita su extensión a otros espacios anatómicos. La mayor parte de los linfangiomas se presentan en el nacimiento (65-75\%) y están presentes a los dos años en el 80 $90 \%$ de las veces. $(3,18)$ Se les consideran el $4 \%$ de todos los tumores vasculares y aproximadamente el $25 \%$ de todos los tumores benignos que afectan a los niños. (1) La incidencia sexual es igual en el hombre que en la mujer, (1) Algunos autores afirman que el linfangioma circunscrito es más común en la mujer, mientras que otros que son más comunes en el hombre, en una proporción de 3:1. No existe predominio racial. (1) Suelen asociarse a síndromes como: síndrome de Turner, síndrome de Nooman, trisomías, anormalidades cardíacas, hydrops fetalis, síndrome alcoholismo fetal y otros síndromes congénitos. No existe riesgo de transformación maligna. (1)

Los linfangiomas se clasifican en (1):

A. Simples o circunscrito: es la forma más común de linfangioma cutáneo, consiste en pequeños vasos linfáticos de aproximadamente $2-4 \mathrm{~mm}$. Estas vesículas claras superficiales pueden variar de color rosado a rojo oscuro según la existencia de hemorragia. Pueden tener aspecto verrugoso en su superficie, confundiéndose con verrugas. (28)

B. Cavernoso: compuesto por grandes dilataciones linfáticas de aspecto nodular. Pueden ser desde 1 $\mathrm{cm}$ de diámetro, hasta ocupar un miembro entero.

C. Quístico (higroma quístico): Son dilataciones macroscópicas quísticas. Se encuentran sobre todo en cuello y área parótida. Muchos autores lo consideran una variante del linfangioma cavernoso. $(1,3)$

Dependiendo del tipo de dilatación de los vasos linfáticos se dividen en:

1. Microquísticas: Si el tamaño de la lesión es de milímetros.
2. Macroquísticas: Si el tamaño de la lesión es de centímetros.

3. Mixtas: Combinación de ambas. Los linfangiomas cutáneos se dividen en dos tipos, superficiales y profundos. Desde este punto de vista esta lesión localizada en labio, puede ser considerada como linfangioma circunscrito superficial. (2)

\section{CASO CLÍNICO}

Estudio epidemiológico observacional descriptivo a propósito de un caso. Se trata de una paciente de 40 años de edad, de sexo femenino, sin alergias conocidas, con antecedentes de tratamiento por síndrome ansioso depresivo. Antecedentes personales para el antígeno de superficie para la hepatitis B y alteración del ritmo intestinal (estreñimiento). Acude a consulta de Odontología en el Centro de Salud de "La Paz" por notar una tumoración en labio inferior de aproximadamente tres meses de evolución, de crecimiento progresivo, aunque últimamente refiere que le ha disminuido de tamaño, sin otros síntomas acompañantes. No refiere hábitos para funcionales como mordisqueo de labio.

En la exploración clínica se comprueba la existencia de una tumoración en mucosa vestibular del labio inferior de 0,5×0,4, excrecente, circunscrita, de consistencia blanda, con superficie lisa y con contenido líquido translúcido (Fig. 1); no se palpan adenopatías, higiene oral deficiente con presencia de calculo, diastemas en incisivos inferiores y falta de piezas dentarias.

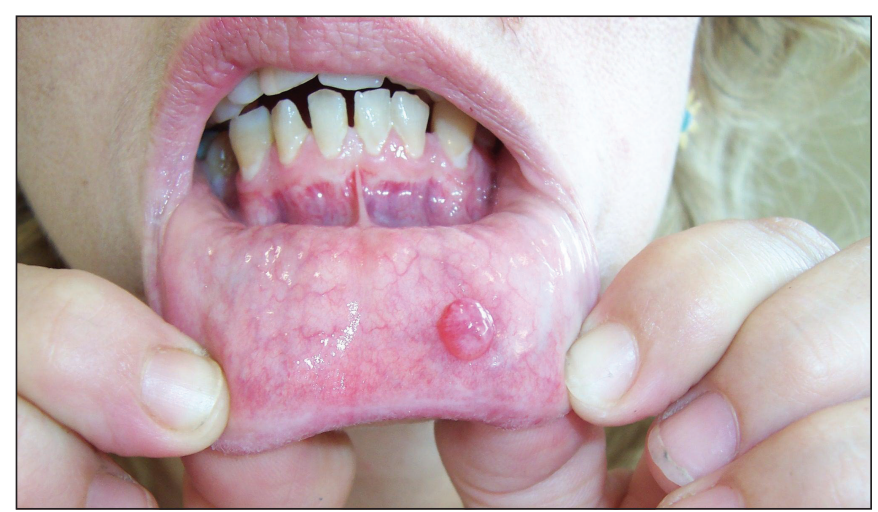

Fig. 1. Imagen macroscópica de la lesión en labio inferior. 
En el estudio radiológico no se aprecian signos de afectación ósea, se descartó la presencia de granuloma por cuerpo extraño. Además la paciente no relata ninguna alteración dental que pudiese relacionarse con la lesión así como no refiere traumatismos previos en labio.

Se realizó una biopsia excisional con remoción completa de la lesión, (Fig. 2) bajo anestesia local infiltrativa con Ultracaín (articaína-epinefrina), sutura con material no reabsorbible (Fig. 3) y fijación de la pieza en formol

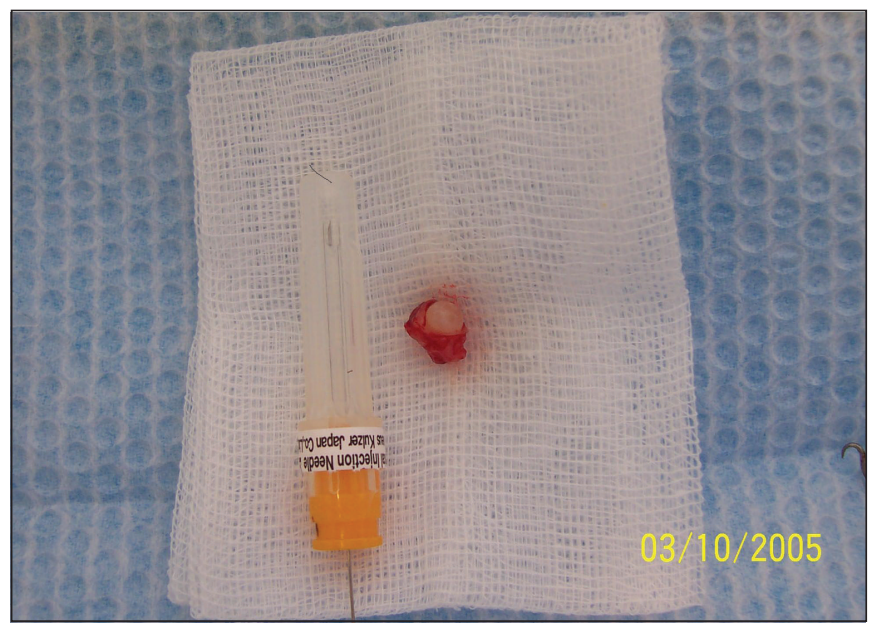

Fig. 2. Pieza anatómica.

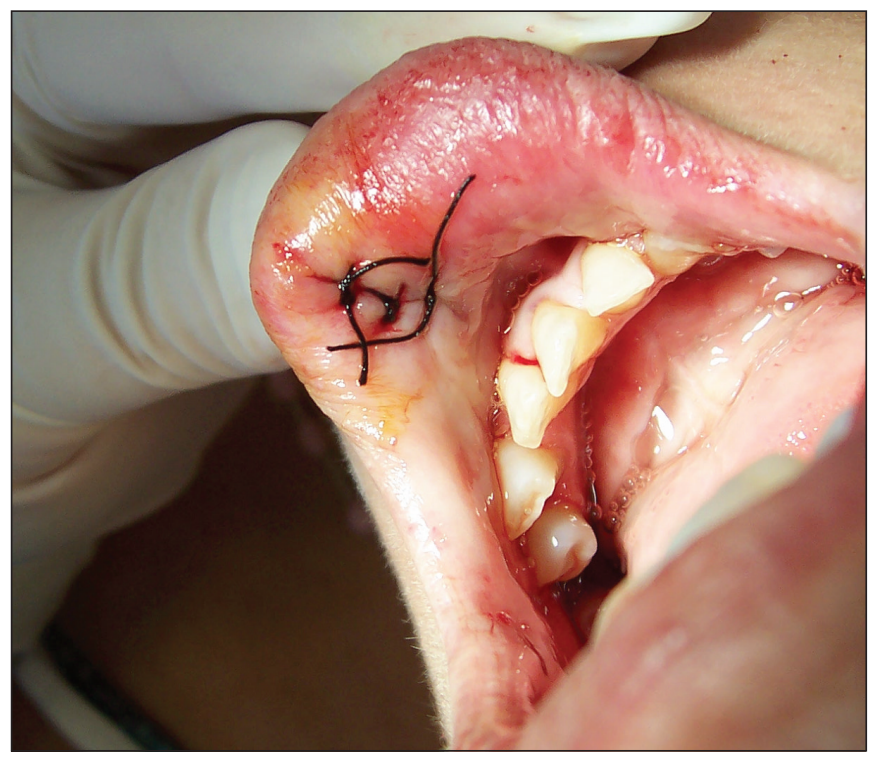

Fig. 3. Sutura. al 10\% para su remisión a estudio anatomopatológico al Departamento de Anatomía Patológica del Hospital Clínico Universitario "Puerta del Mar" (Cádiz), siendo el resultado del diagnóstico de linfangioma. El postoperatorio no presentó complicaciones, solo ligera parestesia en el lugar de la lesión, no observándose signos de recidiva en los controles sucesivos. (Figs. 4 y 5)

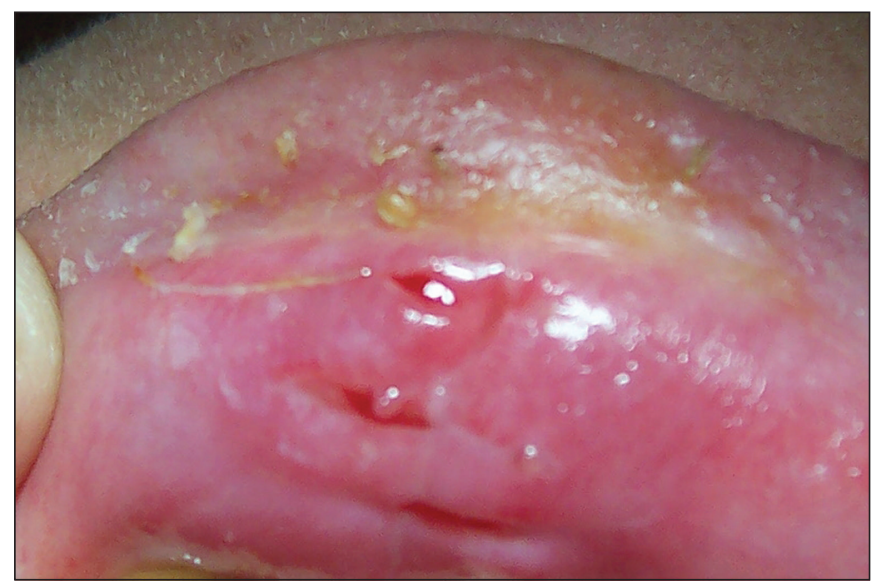

Fig. 4. Aspecto de la lesión una vez retirados los puntos de sutura.

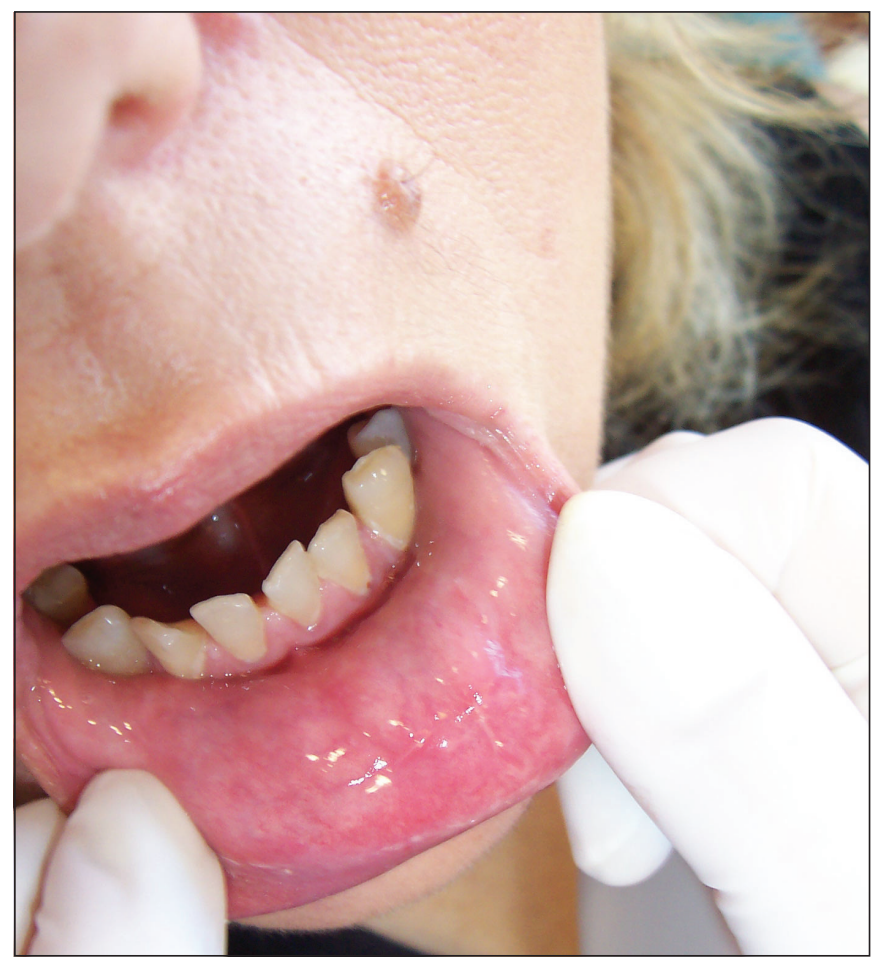

Fig. 5. Estado de la paciente un mes después. 


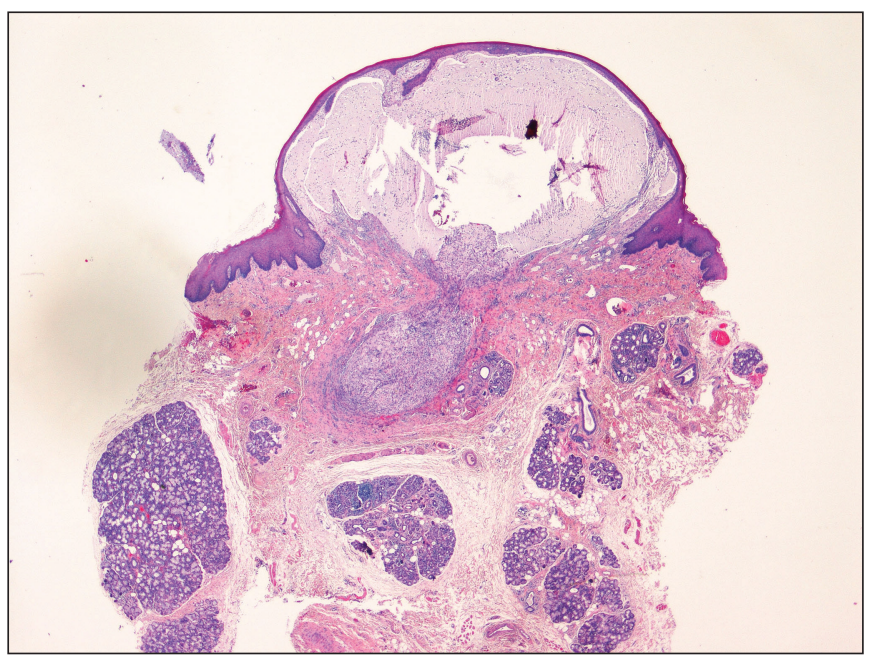

Fig. 6. Sobre elevación nodular a expensas de una formación quística delimitada por collaretes epidérmicos hiperplasicos (hematoxilina-eosina). En su base, le acompaña una proliferación de estructuras vasculares de variable tamaño.

\section{DISCUSIÓN}

Cuando afectan a la boca, su aspecto clínico es variable. Es frecuente su presencia en forma de vesículas translúcidas, por lo general contienen líquido linfático claro, cuyo aspecto se asemeja a los "huevos de rana" o a un "racimo de vesículas translúcidas". $(3,18)$ La piel circundante es normal, a veces con una tonalidad azulada. En la boca la lengua (cara dorsal) en sus $2 / 3$ partes anteriores es el órgano más afectado $(3,4)$, otras localizaciones menos frecuentes en la mucosa oral es el suelo de la boca, mucosas yugales, labios $(3,5,6)$, paladar $(14)$ y gingiva. $(8,18)$ Pueden ser encontrados en pacientes de cualquier edad, en jóvenes y adultos, su origen puede ser desencadenado por un traumatismo accidental o repetitivo $(8,9,20)$, terapéutico (intervención quirúrgica), una hemorragia intralesional, una infección o algún cambio hormonal. Existen pocos casos publicados en la literatura de linfangioma que afecten a mucosa labial y su presentación en personas adultas son descrita como casos insólitos, así como existe gran dilema en su posible origen traumático. $(8,9,14,20)$ Sun y cols. Describen un caso de linfangioma desarrollado en el nervio ulnar, en el cual la lesión fue asociada a un traumatismo. (9) Es el segundo caso relatado de linfangioma que se desarrolló en un nervio y el primero que la lesión se asocia a un traumatismo. Ikeda y

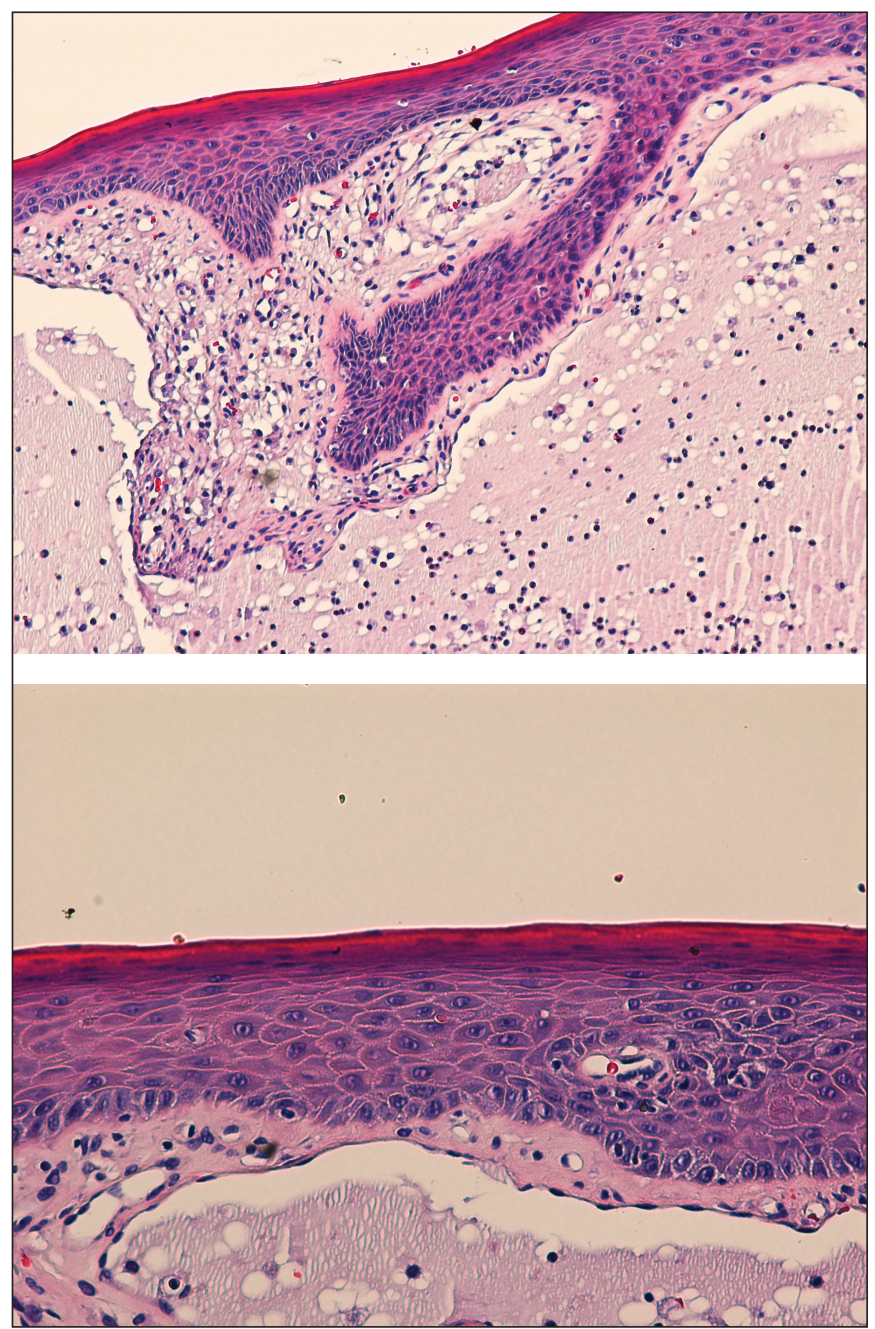

Figs. 7 y 8. Observamos una formación quística revestida de células endoteliales aplanadas sin signos de atipia. La epidermis suprayacente exhibe adelgazamiento e hiperqueratosis.

cols. describen un caso de linfangioma quístico en un varón de 75 años localizado en la punta de la lengua. (12) Antoniades y Aneeshkumar, presentan un caso de linfangioma quístico en un hombre y una mujer adultos, causado por un traumatismo cervical y supraescapular. $(8,23)$ Park y cols. relatan un caso de linfangioma que implica a mucosa oral y mandíbula en una mujer anciana. (13) El examen radiológico y quirúrgico indicaban que la lesión se extendió desde la mucosa labial al periostio y espacio medular de la mandíbula, estando relacionado su extensión mandibular con los cambios osteoporóticos de la vejez. (13) Delbem y cols. relatan la aparición en paladar de un linfangioma circunscrito en un niño de 


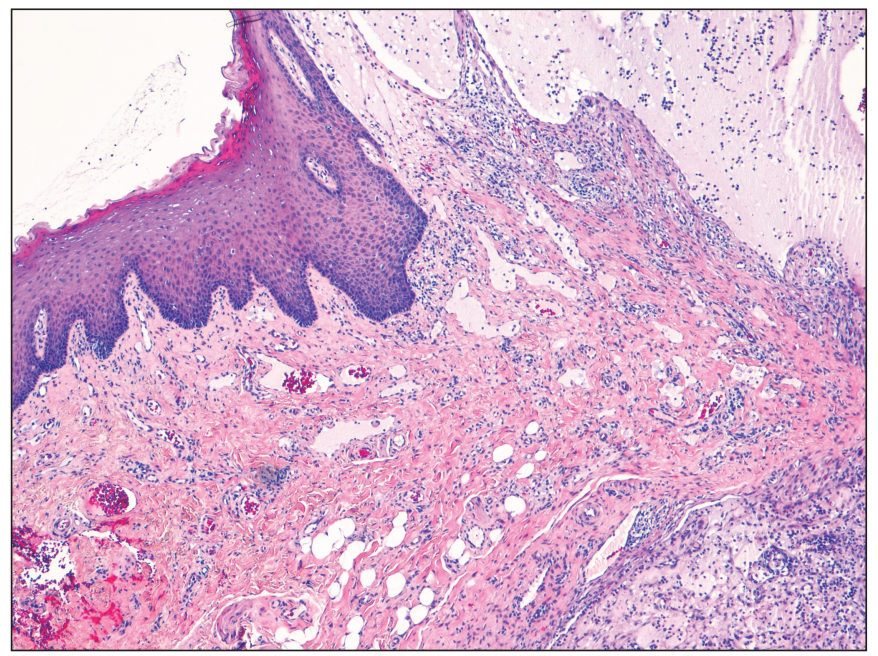

Fig. 9. Proliferación vascular con luces de variable tamaño, exangüe de hematíes ocupados por material proteínaceo y linfocitos.

5 años. La madre relató que había observado la lesión después de una herida traumática con una pluma. El tratamiento indicado fue la supresión quirúrgica ya que la lesión era pequeña y bien delimitada. La evolución fue buena sin signos de recidiva. (14)

El diagnostico es fundamentalmente clínico e histopatológico de confirmación. Un método diagnóstico de linfangiomas es la técnica inmunocitoquímico CD31 la cual permite detectar mediante anticuerpos el receptor 3 del factor de crecimiento del endotelio

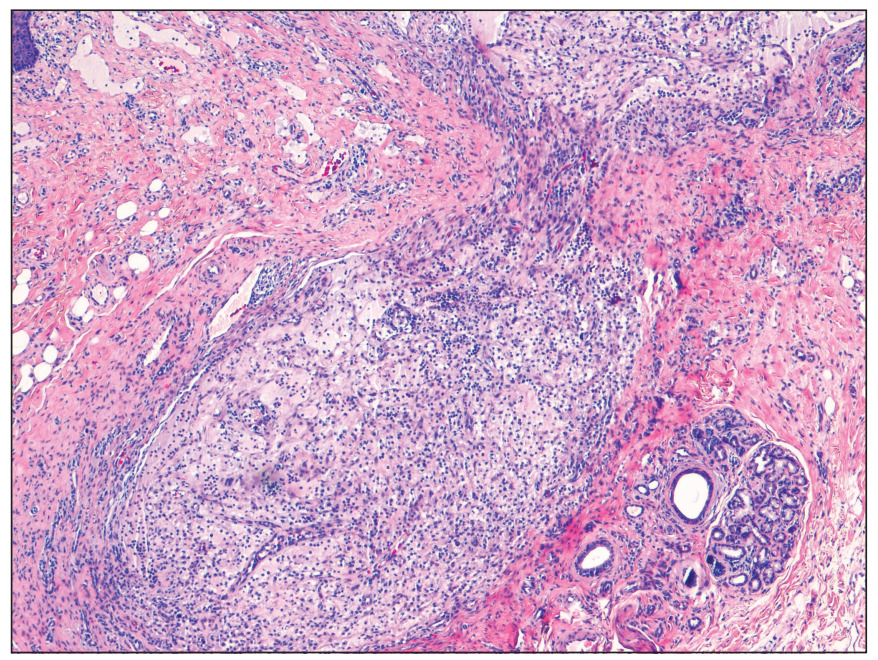

Fig. 10. Presencia de material extravasado que desata una reacción inflamatoria mononuclear bien delimitada.

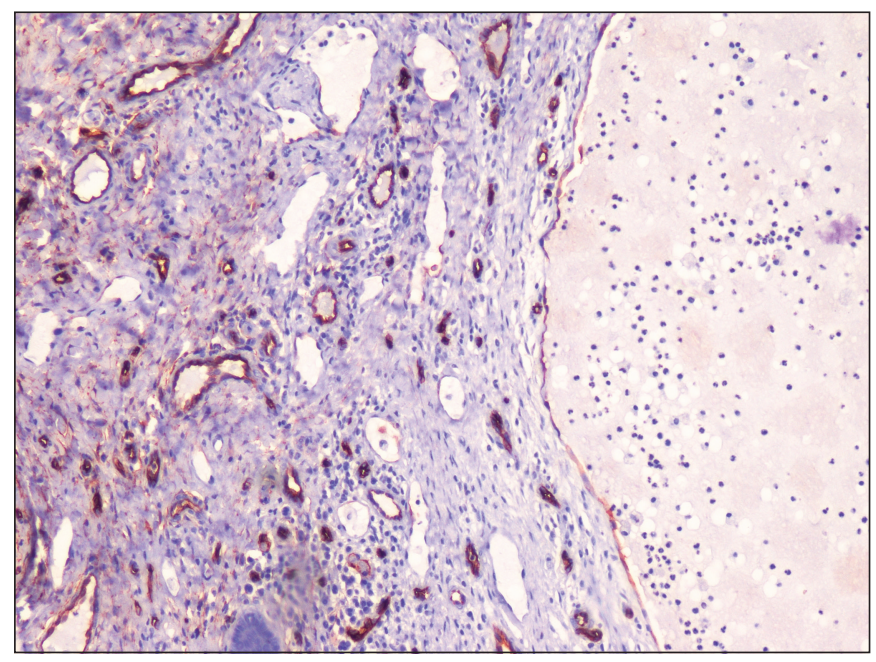

Fig. 11. Positividad de las células de revestimiento, para el marcador citohistoquimico CD 31.

vascular, el cual está presente en mayor proporción en los vasos linfáticos. El marcador endotelial CD31 es una fuente fidedigna para la identificación de células endoteliales linfáticas. $(10,19)$ Este marcador no es especifico para vasos linfáticos (7) existen otros marcadores más específicos como D2-40 y podoplanin. (22)

Se han descrito varias modalidades de tratamiento para el linfangioma:

a) Tratamiento quirúrgico.

b) Tratamiento no quirúrgico:

- Radioterapia (peligro de transformación maligna, debe ser evitada). (1)

- Crioterapia. (1)

- Cauterización. (1)

- Escleroterapia (se difunden a través de la pared delgada del quiste lesionando estructuras adyacentes). Ejem.: Isodine, alcohol, bleomicina, tetraciclina, ciclofosfamida, etc.). (1)

- Administración de corticoides.

- Administración de interferón. (27)

- Embolinización.

- Ligazón.

- Vaporización con láser de dióxido de carbono, con buenos resultados. (1)

- Radiofrecuencia. $(11,24)$

- Uso de OK: 432 Picibanil (Higroma quístico). $(15,21)$

- Solución salina hipertónica. (16) 
La terapia OK-432 es un tratamiento que inyecta OK432 (Picibanil) intralesionalmente a los vasos linfáticos para lograr el encogimiento y/o la desaparición del linfangioma (no es una sustancia esclerosantes), es una mezcla liofilizada del virus Su del tercer tipo del streptococus hemolítico del Grupo A, el cual ha sido incubado con penicilina G. Este producto ya ha perdido la contagiosidad del streptococus hemolítico y bioquímicamente se han perdido también completamente las características de: síntesis con ácidos graso, síntesis con proteína, síntesis con ácidos nucleicos y producción de streptolisin-O y -S. Sin embargo, todavía persiste algo de habilidad para disolver glucosa y la característica típica de la enzima. Esto provoca la inflamación y el infiltrado de neutrófilos, linfocitos y macrófagos y además citoquinas (Interleukina-6 y TNF). Este tipo de tratamiento esta más indicado para linfangioma de tipo cavernoso y sobre todo, para el higroma quístico, dada la dificulta que presentan para el tratamiento quirúrgico y su alta tendencia a la recidiva. $(15,21)$ Una nueva forma de tratamiento para el linfangioma circunscrito es la escleroterapia con solución salina hipertónica al 23,4\%, con efectos secundarios mínimos. (16) En nuestro caso, el tratamiento de elección de este tipo de tumores fue la supresión quirúrgica, dado que la lesión estaba bien delimitada, superficial y por tanto presentaba pocas posibilidades de recidivas. (14)

El diagnostico diferencial se realizara con otras lesiones orales exofíticas (se denomina lesión exofítica a una lesión sólida, excrecente y circunscrita, que hace relieve franco sobre la mucosa oral normal; detectable a la inspección y a la exploración y, generalmente, de consistencia blanda, elástica o duro-elástica).

Entre ellas tenemos lesiones:

1. Infecciosas: Herpes simple, condilomas acuminados, verruga vulgar.

2. Tumores benignos: Lipoma, quiste mucoso, papiloma de células escamosas, neurofibroma, granuloma telangiectásico.

3. Tumores malignos: Carcinoma de células escamosas, melanoma, linfoma, metástasis, Tumores de glándulas menores.

4. Malformaciones: Nevus melanocítico, angioma.
5. Lesiones imitativas: Fibromas, hiperplasia fibrosa, granuloma por cuerpo extraño. (17)

6. Enfermedades ampollosas. (25)

En nuestro caso, hay que destacar la presencia en labio y en una persona adulta, que sólo se menciona en dos de los trabajos consultados, $(5,6)$ siendo la lengua el lugar de presentación más frecuente.

El origen de la lesión, por su corta evolución y presentación, coincide con otros autores en su posible origen traumático. $(8,9,14,20)$

La edad de presentación lo hace un caso insólito. $(8,12,13)$

Por su localización y semejanza, se realizo diagnostico diferencial con otras lesiones de la mucosa oral (Quiste mucoso). (17)

El estudio histológico nos dio el diagnostico definitivo.

El tratamiento en estos casos tan delimitados, coincide con la mayoría de los autores, en que el tratamiento indicado es la extirpación quirúrgica. $(1,3,14)$

\section{CONCLUSIONES}

1. El caso relatado se trata de linfangioma circunscrito superficial en labio inferior.

2. El tratamiento más indicado es la supresión quirúrgica.

3. La edad de presentación en un adulto de 40 años es un caso insólito y su origen es incierto.

4. El diagnóstico siempre es clínico-patológico.

5. Se debe hacer diagnóstico diferencial con otras lesiones de la mucosa oral.

6. El marcador inmunohistoquímico endotelial CD31 fue positivo para las células de revestimiento (células endoteliales).

\section{BIBLIOGRAFIA}

1. Geover Fernandez, MD. Lymphangioma. 2005 Http://emedicine.com/derm/topic866.htm 
2. Weiss SW, Goldblum IR. Tumor of lymph Vessels. In: Weiss SW, Goldblum IR, editor. Enzinger and Weiss's Soft Tissue Tomors. 4. St Louis: Mosby Com; 2001.p.956.

3. Jeeva Rathan J, Harsha Vardhan BG, Muthu MS, Saraswathy K, Sivakumar N, Vekatachalapathy. Oral lymphangioma: A case report. J Indian Soc Pedod Prev Dent. 2005 Oct-Dec;23 (4):185-9.

4. Tei E, Yamataka A, Komuro Y, Oshiro K, Yanai A, Lane GJ, Miyano T. Huge lymphangioma of the tongue: a case report. Asian J Surg. 2003 Oct;26(4):228-30.

5. Miller CS, Craig RM Jr. Bluish dome-shaped nodule of the lip. J Am Dent Assoc. 1999 Jun;118 (6):745-7.

6. Eppley BL, Sclaroff A. Cavernous lymphangioma of the lip: report of case. J Am Denr Assoc. 1985 Apr;110(4):503-4.

7. Pouria Motahhary, Babak Sarrafpour, Afshin Abdirad. Bilateral symmetrical lymphangiomas of the gingival: case report. Diagnostic Pathol 2006, $1: 9$.

8. Antoniades K, Kiziridou A, Psimopoulou M. Traumatic cervical cystic hygroma. Int J Oral Maxillofac Surg. 2000 Feb;29(1):47-8.

9. Sun JC, Maguire J, Zwimpfer TJ. Taumatically induced lymphangioma of the ulnar nerver. Case report. J Neurosung. 2000 Dec;93(6): 1069-71.

10. Galambos C, Nodit L. Identification of lymphatic endothelium in pediatric vascular tumors and malformations. Pediatr Dev Pathol. 2005 MarApr;8(2):181-9.

11. Bozkaya S, Ugar D, Karaca I, Ceylan A, Zulú S, Baris E, Tokman B. The treatment of lymphangioma in the bucal mucosa by radiofrequency ablation: a case report. Oral Surg Oral Med Oral Pathol Oral Radiol Endod. 2006 Nov;102(5): e28-31.
12. Ikeda H, Fugita S, Nonaka M, Uehara M, Tobita T, Inokuchi T. Cystic lymphangioma arising in the tip of the tongue in an adult. Int $\mathrm{J}$ Oral Maxillofac Surg. 2006 Mar;35(3):274-6.

13.Park YW, Kim SM, Min BG, Park IW, Lee SK. Lymphangioma involving the mandible: immunohistochemical expressions for the lymphatic proliferation. J.Oral Pathol Med 2002 May;31(5):280-3.

14.Delbem Ac, Correira MG, Pugliesi DM, Crivelini MM. Palatal Lymphangioma: a case report. ASDC J Dent Child. 2001 Sep-Dic;68(5-6):344-6.

15.Giguére CM, Bauman NM, Sato Y, Burke DK, Grainwald JH, Pransky S, Kelley P, Georgeson K, Smith RJ. Treatment of lymphangiomas with OK432 (Picivanil) sclerotherapy: a prospective multiinstitucional trial. Arch of Otolaryngol 2002 Oct;128(10):1137-44.

16. Bikowski JB, Dumont AM. Lymphangioma circmscriptum: treatment with hypertonic saline sclerotherapy. J Am Acad Dermatol. 2005 Sep; 53(3):442-4.

17. Bermejo-Fenoll A, Lopez-Jornet P. Diferancial diagnosis of exophytic lesions of soft oral tissue. Med Oral Patol Oral Cir Bucal 2005;10:470-1.

18. Cabrerizo-Merino MC, Oñate -Sanchez RE, Romero-Maroto $M$. Hemangiolinfangioma en la infancia: localización inusual. RCOE 2004;9(1): 89-92.

19. Lymboussaki A, Partanen TA, Olofsson B y col. Expressión of the vascular endothelial growth factor $C$ receptor VEGFR-3 in lymphatic endothelium of the skin and in vascular tumors. Am J Pathol 1998;153(2):395-403.

20. Giacomini PG, DE Angelis E, Russo S. Linfangioma cervical dell'adulto: presentazione de un caso significativo. Acta Otorhinolaryngol Ital 1998;18(1):34-7.

21. Okubo T, Shimada T, Narita Y y cols. A success ful case report on intralesional OK-432 therapy 
for cystic mediastinal lymphangiomas. Kyobu Geka 1998;51(12):1017-21.

22. Nelson G, Ordoñez MD. D2-40 and podoplanin are highly specific and sensitive immunohistochemical markers of epithelioid malignat mesothelioma. Hum Pathol 2005; 36:372-380.

23. Aneeshkumar MK, Kale S, Kabbani M, David VC, Cystic lymphangioma in adults: can trauma be the trigger? Eur Arch Otorhinolaryngol. 2005 Apr;262(4):335-7.

24. Lapidoth M, Ackerman L, Amitai DB, Raveh E, Kalish E, David M. Treatment of lymphangioma circumscriptum with combined radiofrecuency current and $900 \mathrm{~nm}$ diode laser. Dermatol Surg. 2006 Jun;32(6):790-4.

25. Vaillant L, Huttenberger B. Acquired bullous diseases of the oral mucosa Rev Stomatl Chir Maxillofac. 2005 Nov; 106(5):287-97
26. White JM, Chaudhry SI, Kudler JJ Sekandari N, Schoelch ML, Silverman S Jr. Nd:Yag and Co2 laser therapy of oral mucosal lesions. J Clin Laser Med Surg. 1998 Dec;16(6):299-304.

27. Souza RJ, Tone LG. Treatment of lymphangioma with alpha-2a-interferon. J Pediatr (Rio J).2001 Mar-Apr;77(2):139-42

28. Horn LC, Kühndel K, Pawlowitsch T, et al: Acquired lymphangioma circumscriptum of the vulva mimicking genital warts. Eur J Obstet Gynecol Reprod Biol 2005 Nov 1; 123(1): 118-20.

\section{CORRESPONDENCIA}

Francisco Javier Rodríguez Romero

C/ General Muñoz Arenillas, 6, piso 9Q

11010 Cádiz

Tfno: 956-289518

E-mail: frrodrom@gmail.com 